\title{
5 The demarcation problem
}

\$1 This chapter returns to the semantic web of terms related to science before modernity, coupling it with the problem of defining and demarcating science from similar human activities today. ${ }^{1}$ Chapter 3 has made clear that in Antiquity, science was not yet a clearly defined single concept - it bore several names - but that its principles were known and practised by some. One might say that the epicentre of what would be science for us today lay somewhere between $\dot{\pi}\lrcorner \sigma \tau \eta \dot{\mu \eta}$, $\varphi \iota \lambda о \sigma o \varphi i \alpha, \tau \varepsilon \dot{\chi} \chi \eta, \mu \alpha \dot{\theta} \theta \mu \alpha$, and iotopía. Although we do have a single name for 'science' from the twelfth century onward, science is, of course, still related to similar activities that mostly also go back to antique concepts. Viewed diachronically, this means that we can envisage a complicated and shifting web of concepts around what we tried to define as 'science' in the previous chapter.

Today, the concept 'science' is related to and stands in some kind of contrast to activities such as religion, magic, philosophy, pseudo-science, and technology. It will be best not to look for a single criterion of demarcation to keep science apart from all these other activities, which is likely to be too wide or too strict. For instance, that of Popper uses falsifiability, which would seem to lead to the exclusion of much of even contemporary natural science. ${ }^{2}$ Today, the human activity most difficult to separate from science may well be what is variously called pseudo-, crackpot, or junk science. In contrast to the other concepts in figure 4, this one arose only after science had established itself as a crucially important category in life, one that had become worth imitating. Unfortunately, there is a lot of such junk science published these days. Gruenberger (1962) half-jokingly proposed an interesting measure for such 'crackpotness'; the factors it takes into consideration are public verifiability, predictability, controlled experiments, Ockham's Razor, fruitfulness, ability to communicate, humility, open-mindedness, Fulton non-sequitur paranoia, ${ }^{3}$ the 'dollar complex', and statistics compulsion. Each of these (or the lack of them) gets a score; the scores are then summed up. The higher the result, the more the author in question is a 'crackpot scientist'. Occasionally, some established scholar or scientist makes fun of junk science tendencies in a field by deliberately publishing junk science that fits into a current mainstream narrative but is completely devoid of scientific content. The most famous example is Sokal (1996); more recently, a paper about 'The Conceptual Pe-

1 In German research this question of demarcating science from similar activities is sometimes referred to as the Abgrenzungsproblem (e.g. Schurz 2008: section 2.5.3, whose discussion is used). 2 As Kuhn points out ([1970] 1998: 14): 'If a demarcation criterion exists (we must not, I think, seek a sharp or decisive one), it may lie just in that part of science which Sir Karl [Popper] ignores.' 3 'They laughed at Fulton. He was right. They laugh at me. Therefore I must be an equal genius.'

ə Open Access. ๑ 2021 Philipp Roelli, published by De Gruyter. (@)BY This work is licensed under the Creative Commons Attribution 4.0 International License. 
nis as a Social Construct' (Lindsay \& Boyle 2017) poked fun at gender theories very much en vogue today. There is even an algorithm for generating random postmodern articles that sound suspiciously like the real thing. ${ }^{4}$ In times when research funding to a unduly large extent depends on fashionable topics, a growing tendency to produce pseudo-science is only to be expected. Pseudo-science may study 'null fields', and '[o]f course, investigators working in any field are likely to resist accepting that the whole field in which they have spent their careers is a "null field". 5 But pseudo-science may also just be bad science using methodology that does not yield trustworthy results; Ioannidis proceeds to show with statistical tools that much of our present-day science is not reproducible and therefore wrong, uncovering a very serious problem, especially in medical and psychological research (the 'replication crisis'). New subcategories of pseudoscience have been proposed: 'pathological science' ${ }^{6}$ or Feynman's (1985: 338) 'cargo-cult science'; indeed, the study of pseudo-science may itself be growing into a scientific sociological discipline. There are already several encyclopaedias of pseudo-science, although none seems to fulfil scientific and scholarly standards.

Returning to human activities similar to science in general, all of them will use some kind of methodology (as required by item (I)), are to some degree coherent within themselves (IV), and may be based on a community (V). Figure 4 tries to display graphically the fact that words are only meaningful in a semantic field where their relation to other words fixes and thus 'defines' them within a web, as has been pointed out (chap. 3 §1). The illustration shows a tentative web of relationships between these concepts for contemporary English. Of course, such graphics made of simple geometric shapes are but a rough indication of complex relationships between terms. The Roman numerals refer to the non-linguistic characteristics listed above; the linguistic ones taken together would differentiate science at least from much of pseudo- or junk science, magic, and religion, but also from much of philosophy, which tends not to have a standardised vocabulary and may lack perspicuitas. ${ }^{7}$ A few clarifications are needed. Religion is taken here

4 http://www.elsewhere.org/pomo, by Andreas M. Q. Scuglia. A large-scale project by three scholars to debunk widespread junk science in current academia was https://areomagazine. com/2018/10/02/academic-grievance-studies-and-the-corruption-of-scholarship, by Helen Pluckrose, James A. Lindsay \& Peter Boghossian. Compare now the theoretical treatment in Pluckrose \& Lindsay (2020).

5 See Ioannidis (2005); for the 'null field', see chap. $4 \S 4$ above.

6 Langmuir \& Hall (1989).

7 Heidegger famously said: 'Das Sichverständlichmachen ist der Selbstmord der Philosophie' ('Making oneself understood is the suicide of philosophy'; 1989: 435). 
as an explanatory device, not in its many other functions, such as ritual, self-realisation, or social rôles. ${ }^{8}$ The distinction between science and scholarship was found above (chap. $1 \S 7$ ) to be typical for the English language. The main difference in a similar graphic for German or the other modern languages studied in chapter 1 would be that 'science' and 'scholarship' would form a single concept. To put the graphic into words: philosophy, except 'natural philosophy' (which is one of the currents that led to modern science), lacks forms of 'testing'; technology lacks a theoretical basis; and pseudo-science may lack impartiality, coherence, and/or formalisation. ${ }^{9}$ Explanatory religion often lacks non-sterility, the ability to explain step-by-step, and impartiality. As an example of a mixture of pseudo-science and religion in this sense, we could think of biblical creationism, which is currently trying to gain equal footing in the US school system with scientific, evolutionary biology. Of course there will be exceptions within all these fields to all these proposed demarcations, but on the whole and taken together, the above items do seem to be able to delineate quite neatly what science is and what it is not in English today.



Fig. 4: An attempt to illustrate the semantic field of 'science' in contemporary English; see the discussion in the main text.

8 In fact, it may be argued that a single category 'religion' encompassing all of these rôles makes little sense outside the Abrahamitic religions. Staal (1996: 401) stresses that '[w]e have found that the trio of ritual, meditation and mystical experience consists of categories that are more fundamental than the category of religion itself'.

9 It is interesting to note in passing that technology developed much more linearly from Antiquity to the present day than science. The many technological advances throughout the Middle Ages seem to happen with little theoretical or even scientific background fixed in writing. See Hägermann \& Schneider (1991). 
\$2 Clearly, such webs of concepts shift with time and between languages (chap. 1 §8). If a similar web for the Greek and Latin counterparts of 'science' is attempted (figs 5-6), things look somewhat different. Figure 5 tries to show the web of terms found in Aristotle (see chap. 3), ${ }^{10}$ although it must be emphasised that Aristotle does not consciously dwell on these differences and sometimes uses some of these terms as synonyms; he does not deal with magic ( $\mu \alpha y \varepsilon i \alpha)$ either, and he is hardly interested in divination ( $\mu \alpha v \tau(\kappa \eta)$ ) ${ }^{11}$ so there are no corresponding terms to English 'magic/superstition' and 'religion'. For him, $\varphi \iota \lambda о \sigma o \varphi$ i $\alpha$ is a very wide term that encompasses everything that produces knowledge and wisdom; voũ entails non-discursive knowledge which is not conveyed by and proven within

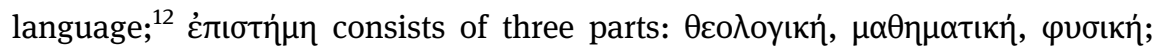
$\delta o ́ \xi \alpha$ is its classical opposite as 'unfounded opinion'; alı $\sigma \theta \eta \sigma \varsigma$, mere 'sense per-

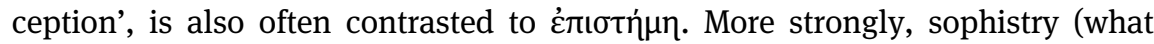
sophists did in classical Greece) may be likened to pseudo-science. iotopí is concerned with non-eternal, changing, often individual things and therefore has a lesser degree of certainty, for which it nevertheless strives. Higher $\tau \dot{\varepsilon} \chi \vee \eta ~ c o u l d ~ b e$ used as a mere synonym of $\dot{\varepsilon} \pi \_\tau \eta \dot{\mu \eta}$, whereas lower, artisanal, $\tau \dot{\varepsilon} \chi v \eta$ is clearly not scientific and not part of philosophy for Aristotle. It must be noted that some of these concepts tend more to denote faculties of the human soul ( $\delta$ ó $\xi \alpha)$ and some more fields ( $\varphi$ ı These two dimensions should be separated in the web, but this would make the graphic too complex; the same is true for scientia in the graphic below.

10 For more details on Aristotle's approach to science, see chap. 7 §5.

11 He treats it cautiously in De divinatione per somnum. For a recent study of the rôle and definition of magic in Antiquity, see Edmonds (2019).

12 This Greek word is very hard to translate. LSJ (s.v. I 5b), has 'Mind, as the active principle of the Universe'; it was the crucial principle of the universe for Anaximander and Anaxagoras. Latin authors often used intellectus for it, but voũ s is not primarily something human. Some mystical authors such as Nicolaus Cusanus use intellectus similarly as something beyond man. Bonitz (s.v.) shows for the Aristotelica notio (in contrast to the general one and those Aristotle quotes from earlier philosophers) among other things that it is always true (ó voṽ $\alpha \dot{\varepsilon i} \alpha \dot{\lambda} \lambda \theta \eta \dot{n}$,

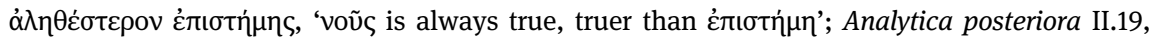
100b11) and that there is an active and a passive voũc, the latter in us and mortal, the $\mu$ ópเov $\tau \tilde{\eta} \varsigma$

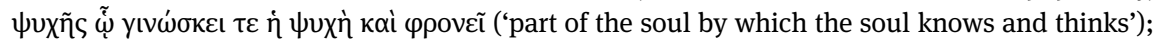
more on this in De anima III.4-5, 413b. 




Fig. 5: An attempt to show the semantic web of Aristotle's concepts around 'science'. For details, see main text.

\$3 Above, it was shown that many of these Greek terms have found a one-to-one correspondence in Latin. A similar diagram is depicted in figure 6 for Latin, but it must be borne in mind that Latin changed over its long history, so this is at best a strong simplification. Although parts of the graphic look similar to the one before, several things are different: disciplina covers a wider field, and scientia sen-


and from the mid-twelfth century onward it usually is. The Middle Ages discussed the question of whether theologia is a part of philosophia or vice versa for a long time, and scientiae and (non-manual) artes were seen as more or less the same thing and often relegated to a subservient role. The relationship between philosophia, scientia, ars, and theologia was hotly debated at least from the twelfth century onward in Latin literature (see chaps 10-11 below). In early modern times, magia split into magic proper (magia ritualis vel daemonica) and magia naturalis, relinquishing powers that have a will of their own ('demons') and becoming a part of scientia that helped to render it more experimental (see chap. 12 §4). Historia, finally, corresponds not only to our 'history', but also partly to 'scholarship' and to the descriptive sciences like naturalis historia, but it is not always clearly differentiated from explanatory scientia; or the former may develop into the latter after enough phenomena have been observed and patterns emerge. Of course, the Latin graphic could also be drawn rather differently and contain some more concepts for authors of the early modern period; for instance, Chauvin speaks of cognitio a lot throughout his long article on scientia, but fails to state how cognitio and scientia relate. For such authors, scientia becomes a very general term for all 'serious' knowledge gathered with sound methodology. Thus, philosophia, historia, theologia, and ars would be encompassed by scien- 
tia. ${ }^{13}$ This is by and large the usage found in the vernacular languages German, French, Russian, and Modern Greek (see chap. 1 above).

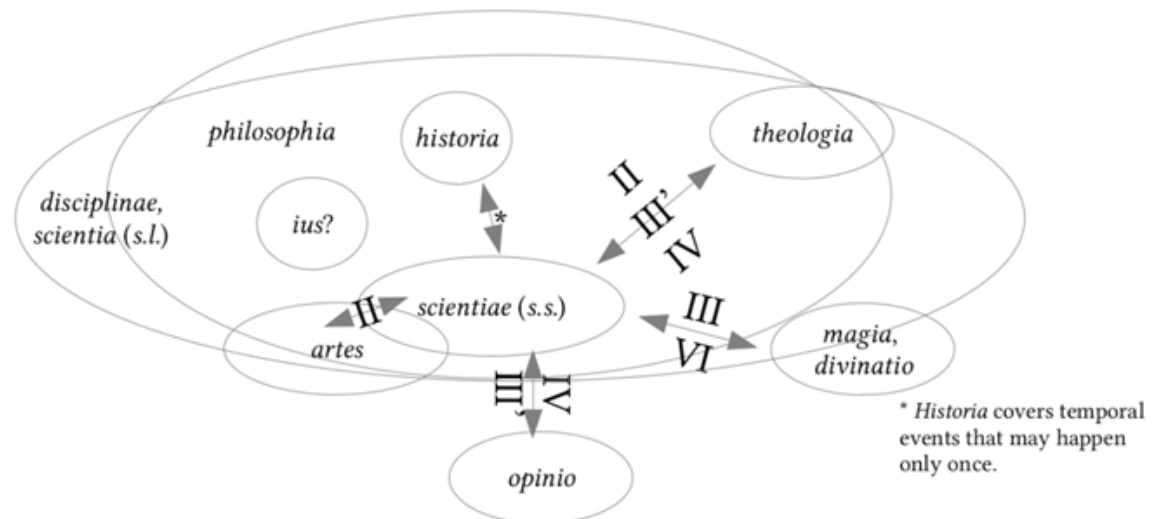

Fig. 6: A similar web for Latin concepts, including scientia sensu lato and sensu stricto. The exact position of the Latin ius within the Greek disciplinae remains unclear.

Simplifying matters even more, the following rough semantic correspondences or developments between Greek, Latin, English, and German can be discerned:

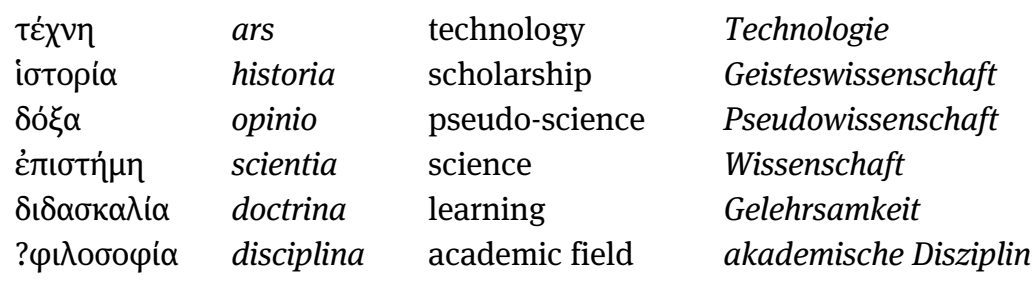

Although some items in this grid could be positioned differently, it would seem that there is at least a strong diachronic trend linking the concepts. The final set of correspondences is rather tentative, indicating the 'wider frame'. A more diachronic perspective will now be taken, especially for Latin authors through this language's extraordinarily long lifespan. Many of the issues discussed in this first part will become clearer and more nuanced as a result of this examination of the actual textual material.

13 Sanabria (2003: 51-60) discusses various positions regarding the relationship between science and philosophy today. Some Latin passages were discussed in chap. $3 \S 6$ above. 